\title{
The Innovation Effect of User Design: Exploring Consumers' Innovation Perceptions of Firms Selling Products Designed by Users
}

The authors study consumer perceptions of firms that sell products designed by users. In contrast with the traditional design mode, in which professional designers employed by firms handle the design task, common design by users involves the firm's user community in creating new product designs for the broader consumer market. In the course of four studies, the authors find that common design by users does not decrease but actually enhances consumers' perceptions of a firm's innovation ability. This "innovation effect of user design" leads to positive outcomes with respect to purchase intentions, willingness to pay, and consumers' willingness to recommend the firm to others. The authors identify four defining characteristics of common design by users that underlie this innovation inference; namely, the number of consumers, the diversity of their background, the lack of company constraints, and the fact that consumer designers actually use the designed product all contribute in building positive perceptions. Finally, the authors identify consumer familiarity with user innovation and the design task's complexity as important moderators that create boundary conditions for the innovation effect of user design.

Keywords: product design, co-creation, user design, user innovation, innovation

$\mathbf{T}$ raditionally, professional designers at companies were exclusively responsible for designing products for the consumer marketplace. However, recently, various industries have developed many new products that were not developed by designers working at firms but rather by the users themselves (Von Hippel 2005). For example, a recent survey of a representative sample of U.K. consumers revealed that $6 \%$, or almost 3 million consumers, innovated in the domain of household products, and in aggregate, annual product development expenditures of users has been found to be 1.4 times larger than the respective expenditure invested by all U.K. firms combined (Von Hippel, De Jong,

Martin Schreier is Professor of Marketing, WU Vienna University of Economics and Business (e-mail: martin.schreier@wu.ac.at). Christoph Fuchs is Assistant Professor of Marketing, Rotterdam School of Management, Erasmus University (e-mail: cfuchs@rsm.nl). Darren W. Dahl is Fred H. Siller Professor in Applied Marketing Research, Sauder School of Business, University of British Columbia (e-mail: darren.dahl@sauder.ubc.ca). The first two authors contributed equally; the order of names was determined by flipping a coin. The authors thank JoAndrea Hoegg and Emanuela Prandelli for their feedback on earlier versions of this article, Ajay Kohli for his help on the positioning of this article, and the three anonymous $J M$ reviewers for their help and guidance during the review process. The authors are also grateful to Julia Bauer, Elena Bellio, Katharina Braun, Luca Casulli, Hans-Jórn Juhl, Ursula Christine Loisch, Rebecca Mocellin, Barbara Mueller, Mihai Oprisa, Paola Pasquale, and Laura Vaida for their help with the studies. Finally, the authors acknowledge financial support from the Erasmus Research Institute of Management and the CERMES Research Center at Bocconi University (previous affiliation of the first author). Ajay Kohl served as area editor for this article. and Flowers 2012). A concrete example of commercial user innovation is open source software (e.g., Apache, Linux), which is jointly developed by a community of users and competes with products developed inside firms. As a second example, consider Threadless, a fashion company that specializes in the mass marketing of user-designed hip Tshirts (Ogawa and Piller 2006).

The underlying phenomenon - that certain users are able and motivated to innovate and are willing to share their ideas with firms - is not new and has been documented extensively (e.g., Von Hippel 2005). However, what is new and notable about Threadless and similar firms in several consumer goods fields (e.g., apparel, household products, sports equipment) is that such firms have begun to almost completely "outsource" the front end of new product development (NPD) to their user communities on a permanent basis. They market the best of these user ideas as common products to the masses and, most important, stress that these products are designed by users (common design by users) in their communication efforts. Like Threadless, in which the individual user-designers are prominently featured on the company's website and on the tag inside the T-shirts ("Threadless - [designed] by user name"), LEGO, for example, has also begun to sell products designed by members of its huge user community with the label "designed by LEGO fans" printed prominently on the product's packaging.

What are the implications of this trend? In calling for research in this area, Moreau and Herd (2010) indicate that this phenomenon has implications for both the participating users and the broader market as a whole. We seek to con- 
tribute to this emerging stream of research by analyzing how nonparticipating users in the broader market-"observing" consumers who constitute the mass of potential customers for those products (Fuchs and Schreier 2011) - actually perceive companies that pursue common design by users. Indeed, being innovative with new products is one thing; being perceived as innovative, however, is another (Brown et al. 2006). Will consumers perceive such firms to have higher or lower innovation abilities? This question underlies the goal of our research - namely, to provide an understanding of how perceptions of innovation ability, defined as a consumer's belief that a company is able to generate more innovative products (Brown and Dacin 1997; GürhanCanli and Batra 2004), are linked to a user design inference. ${ }^{1}$ We argue that it is crucial to explore such a potential if-then linkage among consumers because this could explain relevant downstream effects such as potential differences in purchase intent for products designed by professional designers versus users.

In theoretical terms, we draw on the consumer inference literature, which broadly posits that "inference formation involves the generation of if-then linkages between information ... and conclusions" (Kardes, Posavac, and Cronley 2004, p. 230; Kruglanski and Webster 1996). Inferences are important because consumers often have limited information about firms and their products and, as a result, combine the limited information available with their beliefs to develop theories and make related judgments and decisions (e.g., price-quality, country-of-origin-based inference; e.g., Hong and Wyer 1989; Huber and McCann 1982). Guided by practical examples, this analysis is limited to consumer product categories because these categories are where firms

1When we refer to "innovation," we adopt its classic definition: designing products that are new and useful (Sethi, Smith, and Park 2001). increasingly draw on users to fuel their NPD pipelines and promote common design by users in their communications. As such, it would be unrealistic and thus uninteresting substantively to study consumer perceptions of firms operating in more industrial product categories such as the fuel cell or biotech industries.

Across four studies, our research contributes to the literature in several important ways (see Figure 1). Foremost, our studies are the first to demonstrate that common design by users indeed enhances consumers' perceptions of a firm's innovation ability with respect to product outcomes that result from this practice - an innovation effect of user design. Second, we find that this effect is of substantive importance because it mediates positive outcomes with respect to (1) consumers' purchase intentions, (2) willingness to pay, and (3) willingness to recommend the firm to others. Third, we identify four defining characteristics of common design by users that underlie this innovation inference: the number of consumers that participate in user design, the diversity of their background, the lack of constraints that consumers face compared with company designers, and the fact that consumer designers actually use the designed product themselves. These characteristics all contribute to building positive perceptions. Fourth, we identify consumer familiarity with user innovation and the design task's complexity as important moderators that create boundary conditions for the innovation effect of user design.

\section{Common Design by Users}

Drawing on design theory terminology (Ulrich 2007), a firm that permanently and exclusively empowers its user community to generate promising ideas for new products is defined to be one that fosters "common design by users" (as opposed to design by professional company designers). The

FIGURE 1

Overview of Studies

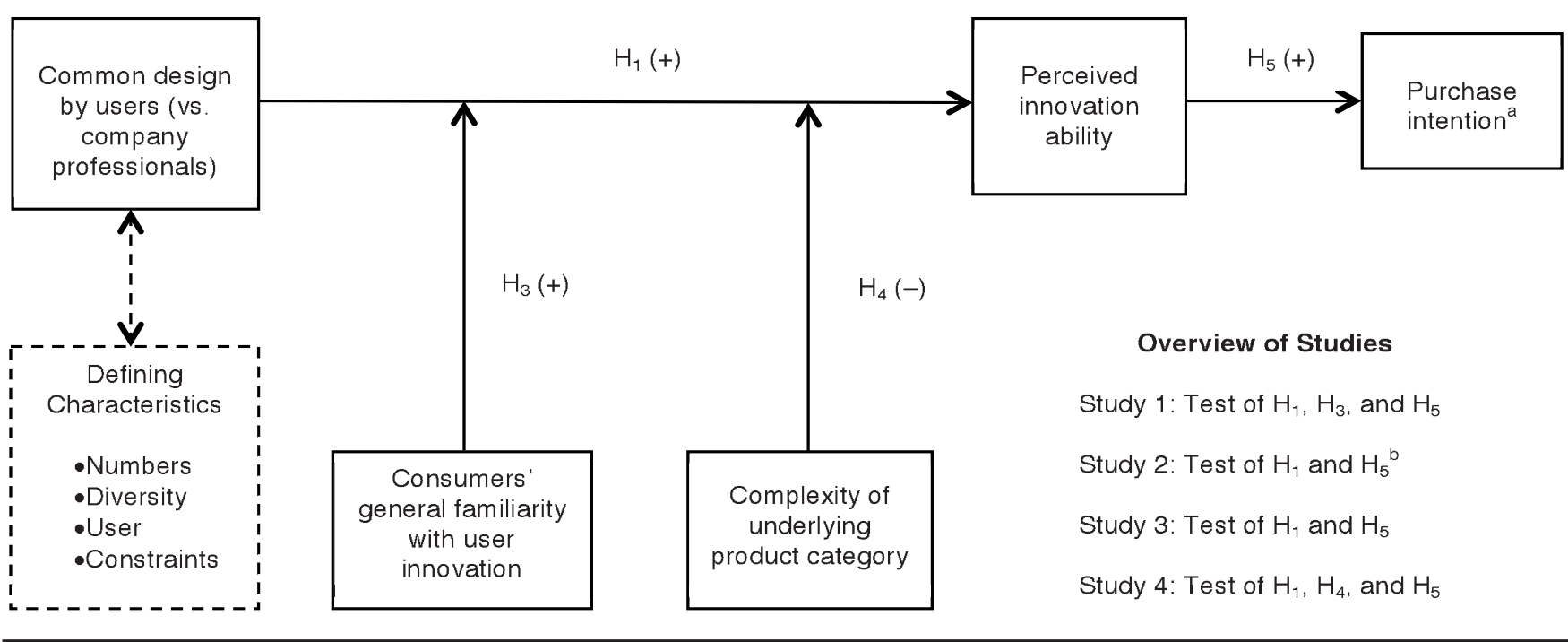

aAdditional outcome variables: Willingness to pay (Study 3); intention to recommend product and firm to others (Studies 2 and 3 ).

bThis study also validates the defining characteristics of common design by users (test of $\mathrm{H}_{2}$ ). 
word "common" (as opposed to "custom") is important because it highlights that such firms market the best of such user-designed products to the broader consumer market; that is, users take on the role of designers to generate ideas that might be appealing to entire customer segments. This is in sharp contrast to other customer empowerment strategies such as mass customization, in which individual customers merely design custom products for themselves, which the firm then exclusively produces to order for that customer (e.g., Franke, Schreier, and Kaiser 2010).

Traditionally, common products are designed exclusively by professionals working for the underlying firms because those people "have acquired skills and capabilities that allow them to perform most design tasks more effectively and at a higher level of quality" (Ulrich 2007, Chapter 3, pp. 5-6). However, over the past few years, this design mode has become blurred as more firms have begun to appreciate the value of actively integrating selected users in the design process for common products. This has been stimulated by repeated observations that many user modifications of existing products as well as user designs of completely new products are actually highly attractive innovations on the market; thus, the products were attractive not only to the individual user-designer but also to broader parts of the market (Von Hippel 2005).

As we noted previously, this trend is now being pushed even further by firms such as Threadless, which has brought about a design mode in which idea generation, the fuzzy front end of NPD, is exclusively in the hands of users and firms select the best of these user designs, rework them if necessary, and market them as common products "designed by users" to the general public. To disentangle the perceived value of professionals versus users, we aim to contrast both extremes of this continuum - that is, design by company designers and common design by users.

\section{Understanding Innovation Perceptions of Common Design by Users}

On first consideration, it could be argued that even for relatively simple design tasks for products such as breakfast cereals, T-shirts, LEGO toys, and household products, compared with a firm's professional design, common design by users might be perceived as an inadequate means of creating truly new and useful products. Managerial wisdom supports this conjecture: For example, Bennett and Cooper (1981, p. 54) argue that a truly creative idea for a new product "is very often out of the scope of the normal experience of the consumer," and Schulze and Hoegl (2008, p. 1744) note that "relying on the method of asking buyers to describe potential future products, big leaps to novel product ideas are generally not likely."2 Furthermore, consumers might also think that a firm that touts common design by

2It is important to point out that the focus of this research is not on the "objective" promise of the NPD approach of common design by users (e.g., the innovative nature of related products compared with products generated by competing design modes; see Von Hippel 2005) but rather on consumer perceptions thereof. users has lower innovation abilities. This is because "professionals often have a significant advantage, either real or perceived, over consumers, in terms of their knowledge, training, and experience" (Moreau and Herd 2010, p. 807, emphasis added). Therefore, when contrasting users with company designers, it is reasonable to think of an "upward" comparison, with professionals at a higher position on the ability scale (Moreau and Herd 2010).

Thus, traditional inferences of expertise and skill are likely to work against positive innovation perceptions of common design by users. However, the success of firms that have exclusively adopted user design, such as Quirky (consumer goods) and Threadless (T-shirts), as well as successful user-driven initiatives at more traditional firms that maintain professional designers, such as Muji (furniture) and LEGO (toys), point to the possibility that consumers do carry positive innovation perceptions of common design by users. What inferences would underlie and define a positive innovation effect in this regard? As a first step toward exploring this question, we conducted 22 semistructured interviews (55\% female; nonstudent sample) following the procedures Strauss and Corbin (1998) suggest. These interviews began by defining common design by users, illustrated using Threadless as an example. This was followed by questions related to the underlying company and its products. Significantly, responses to this questioning showed that the positive attributions expressed by interviewees toward the company (common design by users) were most often driven by perceptions of strong innovation abilities - what we have defined as an "innovation effect of user design." More important, when probed on their justification for this inference, interview participants indicated four defining characteristics of organizations that utilize common design by users that underscored their positive reaction. In the following subsection, we identify each of these factors and provide a rationale for why they might justify a positive innovation inference among the broader consumer market.

\section{Why Common Design by Users Might Increase Perceived Innovation Ability}

The numbers argument. The first characteristic identified in the interviews entails a simple numbers argument: Consumers perceive far more people behind firms that employ common design by users than behind those that use company designers. As Interviewee 15 stated, "the more heads are involved, the more creative ideas will pop up." Indeed, companies are subject to natural financial constraints and can only hire a certain number of professional designers. A user community, in contrast, might consist of thousands of interested and talented users. The Threadless user community, for example, consists of more than 800,000 registered users who submit 150-200 new designs a day, of which an average of 9 new T-shirts are selected to sell each week. What follows is a popular quantity-quality inference (Osborn 1963): The more ideas on the table, the more likely it is that highly creative new products will result (Troy, Szymanski, and Varadarajan 2001; Valacich et al. 1995; Van Gundy 1988). As Terwiesch and Ulrich (2009, p. 
28 ) indicate, "If you produce more opportunities, you'll see more exceptional ones... Creating more opportunities ... is thus a key lever in finding the exceptional few" (see also Diehl and Stroebe 1987). Thus, a reason consumers might attribute higher innovation abilities to firms that employ common design by users may be grounded in the idea that quantity breeds quality. Importantly, this inference does not imply that the average quality of user ideas is any higher than those of company professionals (which seems unlikely). Instead, it implies that the greater quantity of user ideas increases the likelihood of generating some ideas with exceptionally high quality.

The diversity argument. A second fundamental characteristic interviewees identified is the perceived diversity inherent in common design by users. As in the numbers argument, consumers may perceive a user community to consist of people who are more diverse in terms of background, interests, skills, and so on, compared with a small subpopulation of designers that might only partly mirror the diversity of the general public (Rigby and Viswanath 2006). Although this might be empirically related to size (i.e., more people create more diversity), it is conceptually distinct from that attribute. A potential difference in perceived diversity is important because it is a common belief that diversity affects creativity because it yields different perspectives and ideas (Mannix and Neale 2005; Robinson and Dechant 1997). Conversely, if contributors to creative processes have similar backgrounds, the resulting ideas are likely to be similar (Sethi, Smith, and Park 2001). As exemplified in an Interviewee 16's statement, "because so many different people can participate ... [and] many different ideas come together,... there will most probably be many, many innovative designs."

The user argument. A third underlying factor revealed in the interviews lies in the nature of the groups involved: Consumers may associate common design by users with higher innovation ability simply because users belong to the same population as the consumer and thus share characteristics inherent to group membership. In contrast, company designers are not necessarily consumers or users; at least their role might cause them to be primarily perceived as a designer rather than a user. As such, they might not be aware of-or may misinterpret-consumer needs and wants, and they might be viewed as not being directly exposed to the consumers' problem situations and/or as not living in the consumers' environments (Von Hippel 2005). As Interviewee 2 stated, "I think that users are more likely to have such [good] ideas.... [Professional designers] do not see the real issues." Indeed, it seems user-designers as consumers are perceived as having rich insight into unresolved consumption problems, which might provide them with multiple starting points to generate novel and useful ideas (Von Hippel 2005).

The constraints argument. Finally, many interviewees perceived users as being less constrained by specific company requirements such as profit targets, deadlines, corporate design conventions, brand positioning, and so on. "Company designers act within predefined design 'pigeon holes'; users ... [are] not bound by any conventions or ... specific sales expectations" (Interviewee 14). In turn, this difference in constraints or freedom in design should affect perceived innovation abilities: "Users need not pay attention to any guidelines.... They can do whatever they want.... They have more freedom than a company designer, who has to design within a company's master profile.... [Common design by users] is more open to truly new things" (Interviewee 11). Thus, users will be less constrained and might therefore more easily allow their visions and ideas to flow in whatever direction they want. In contrast, company designers' creativity might be viewed as being curtailed because it is subordinated to higher-order corporate goals and constrained by formally structured processes.

In summary, we argue that these underlying characteristics are what make the design mode of common design by users different from design by company professionals. If consumers perceive users as having less expertise than designers but still assign greater innovation attributions to firms fostering common design by users, these defining characteristics, or arguments, might help shed light on such a counterintuitive effect-namely, that common design by users might indeed be associated with higher innovation abilities. As a first step, we aim to experimentally validate the existence of a positive inference of innovation ability for common design by users and confirm that these identified characteristics do indeed define the phenomenon. Formally,

$\mathrm{H}_{1}$ : Consumers associate firms fostering common design by users (vs. design by company designers) with higher innovation ability (i.e., an innovation effect of user design).

$\mathrm{H}_{2}$ : The innovation effect of user design can be explained by (a) number, (b) diversity, (c) user, and (d) constraints arguments.

\section{Qualifying the Innovation Effect of User Design}

We do not expect that the "innovation effect of common design by users" is universal; rather, we predict that it will depend on the extent to which observing consumers perceive users as being capable of meaningful design. In particular, the effect should depend on at least two boundary condition variables that have actionable implications: (1) observing consumers' familiarity with user innovation and (2) the perceived complexity of the underlying product (i.e., the respective design task complexity).

Regarding the first boundary condition, familiarity with user innovation, there is an expectation that the likelihood of realizing an innovation effect of user design increases when consumers have familiarity with the concept of user innovation (familiarity with user innovation is defined as the extent to which consumers have had ideas for modifying products themselves or know peers who have created their own innovations). This prediction is backed by the well-established literature in social cognitive psychology that states that people generally project their own characteristics, beliefs, and attitudes onto others (Holmes 1968; Kawada et al. 2004; see also Ross, Greene, and House 1977). Accordingly, consumers who are familiar with user innovation are likely to project a proactive user stereotype onto other users in other domains when confronted with a 
firm pursuing common design by users. In contrast, consumers who are not familiar with user innovation are unlikely to make these attributions and will not perceive user innovation in a meaningful way. Formally,

$\mathrm{H}_{3}$ : The innovation effect of user design is attenuated for consumers with low familiarity of user innovation.

Regarding the second boundary condition, perceived complexity, we expect that the innovation effect of user design will be mitigated as perceived design task complexity increases. A design task is complex if the process of design requires a wide variety of distinct skills and types of expert knowledge of technology, materials, and processes (e.g., Hobday 1998; Novak and Eppinger 2001). Thus, as Campbell (1988, p. 45) notes, "Complex tasks are, by their nature, difficult." For our context, we consequently adopt the following holistic definition: Design task complexity is the extent to which consumers perceive a product to be difficult to design (Rogers 1995; with "difficulty" referring to the extent to which expert skill and knowledge is necessary for successful design).

Although lead users are frequently observed to come up with attractive user innovations in more complex fields (e.g., Lettl, Herstatt, and Gemuenden 2006), the perceived relative advantage of common design by users over design by professional designers is likely to diminish as the need for design expertise that is inherent to complex design becomes more central in achieving design success. Indeed, some interviewees pointed to more complex product categories (e.g., technical design of skis, cars, personal computers) for which their overall reaction to a common design approach became more critical-mostly due to a lack of perceived user expertise (e.g., "a user might not get something valuable, he lacks the technical knowledge ... with technical details of skis, users will have problems, they don't understand the technical components" [Interviewee 20]). While the perceived necessity of expertise in fostering innovation might be weak for more simple design tasks, such as designing a new breakfast cereal or a T-shirt, it is likely to get much stronger for more complicated design tasks such as designing consumer electronics or robotic toys (e.g., those designs done by the LEGO community Mindstorms). Therefore, if the underlying design task is highly complex, it might not help the firm from a consumer perspective to have a user-centered design focus. Thus:

$\mathrm{H}_{4}$ : The innovation effect of user design is attenuated for products high in design complexity.

\section{Why Perceptions of Innovation Ability Matter}

Why should potential effects on consumers' perceptions of a firm's innovation ability matter to firms? We argue that innovation ability perceptions might affect the way consumers view and evaluate the underlying firm and its products. As Gürhan-Canli and Batra (2004, p. 197) indicate, consumers indeed use such "corporate associations in evaluating new products" (see also Brown and Dacin 1997). This type of attribution regarding a firm is thus likely to directly affect consumer behavior beyond any concrete products the firm offers. Importantly, researchers have pro- vided broad empirical evidence on the link between consumer perceptions of a firm's innovation ability, the innovativeness perceptions of its products, and positive outcomes with respect to consumers' purchasing behavior and related satisfaction (Chun and Davies 2006; Szymanski, Kroff, and Troy 2006; Troy and Davidow 1998; see also Luo and Bhattacharya 2006). Therefore, we posit that consumers will demonstrate a stronger demand for products of firms pursuing common design by users because of higher innovation ability perceptions. Formally,

$\mathrm{H}_{5}$ : Consumers develop more favorable behavioral intentions (i.e., purchase intent) toward firms fostering common design by users (vs. design by company designers). This effect is mediated by the innovation effect of user design (higher perceived innovation ability).

\section{Overview of Studies}

We test the hypotheses presented across four studies. Using the context of breakfast cereal innovation, Study 1's purpose is to validate our central prediction by establishing the positive nature of the innovation effect for user design $\left(\mathrm{H}_{1} / \mathrm{H}_{5}\right)$. Furthermore, we explore how consumer familiarity with common design by users is central to establishing the effect $\left(\mathrm{H}_{3}\right)$. Study 2 builds on this initial study by validating the defining characteristics of this effect in the context of T-shirt design $\left(\mathrm{H}_{2}\right)$. Study 3 strengthens the generalizability of the innovation effect of user design by showing its effectiveness when executed in packaging communications and in both aesthetic and functional design contexts. Finally, Study 4 tests the second boundary condition, showing that this perceptual effect is more robust when design task complexity is relatively low $\left(\mathrm{H}_{4}\right)$.

\section{Study 1}

\section{Method}

For Study 1, 80 students participated (55\% female) and were randomly assigned to one of two groups (common design by users vs. design by company designers). Guided by practical applications, we chose breakfast cereals as the first product category to study (e.g., Muesli allows users to design their own breakfast cereal mix; http://uk.mymuesli. $\mathrm{com} /$ ). All participants first read standardized background information about the underlying company ("Company A [real brand name blinded] is a company that specializes in cereals"). Importantly, both groups were informed that "as with many firms nowadays, this company has an online user-community." We added this cue to avoid any confounding effects from having a community (vs. marketing products designed by users). Participants then inspected color pictures of "products which have recently been marketed by this firm" (pictures of breakfast cereal mixes including written descriptions of the ingredients taken from Muesli).

Thus, participants in both groups were exposed to identical concrete product stimuli before treatment. This mimics the practical situation in which consumers might see a firm's products first and only afterward learn about the firm's practices (and form specific ability associations). We 
also believe that this provides a stricter test of $\mathrm{H}_{1}$ than a scenario without concrete pretreatment product exposure. Indeed, in the latter case, there is only one cue available to participants - the secondary association regarding the company's design mode - while in the former case, there are two cues - the concrete product stimuli (constant between groups) and the abstract design mode (manipulated). However, note that we also tested this alternative scenario and found parallel results (results can be obtained from the authors).

Participants then received their group-specific treatment; they were provided background information about the company's design approach. In particular, Group 1 was told that the new cereal mixes are "designed by company professionals"; that is, they were informed that for this firm, new products are regularly and exclusively designed by professional product designers who work for Company A (design by company designers). In contrast, Group 2 was told that the new cereal mixes are "designed by users"; that is, they were informed that for this firm, new products are regularly and exclusively designed by members of Company A's user community (common design by users).

Next, participants completed a questionnaire that captured our dependent variables and some control questions. Table 1 lists all measures and item sources. To measure consumers' perception of the company's innovation ability $\left(\mathrm{H}_{1}\right)$, participants were first provided with the construct definition (a company's innovation ability refers to its ability to develop new and useful products), followed by the preamble "What do you think about the firm's innovation ability?" We used a three-item scale (e.g., "I think this company's ability to innovate is not very high/very high"; $\alpha=.89$ ).

To test $\mathrm{H}_{5}$, the downstream measure, purchase intention, comprised five items (e.g., "To me, purchasing a product from this company is very unlikely/likely"). To avoid any state-dependence effects, we used scales with varying scaling formats (e.g., Likert, semantic differential, vertical [Juster] scales), and varying scale points (7- and 11-point scales; see Table 1). We averaged the standardized items scores, which loaded on a single factor, to form a purchase intention index $(\alpha=.87)$. We counterbalanced the order of the measures for innovation ability and purchase intent to test for order effects (subsequent analysis showed no order effects).

After the dependent variables, we measured the following control variables. First, participants indicated how "new" they perceived the company's business model to be (i.e., the company's way of developing new products). We added this single-item measure to address whether the mere newness of the business model might constitute an alternative account (i.e., it could be argued that it might not be the specific nature of common design by users but rather the relative newness of the design approach that might drive innovation ability or simply create a positive halo effect). Second, participants were asked how much attention they paid to the way the company develops new products to test whether one condition was more salient than the other. It could be argued that common design by users is more salient because of recent attention it has afforded, which might cause higher scores on innovation ability. Third, we captured consumer perceptions of the design expertise of those designing for the underlying company with two items $(\alpha=.87)$.
To test $\mathrm{H}_{3}$, we measured participants' general familiarity with user innovation using three dummy items that formed an additive index (e.g., "Have you ever developed a product yourself-either modifying an existing product or creating a new artifact from scratch?"). Finally, participants speculated about the underlying research question of the study (in this and subsequent studies). However, a thorough inspection of participants' ideas revealed that only seven participants (across all four studies) indicated an awareness of the study intent. We eliminated them from further analysis (though results do not change if we retain them).

\section{Findings and Discussion}

Most important, and in support of our main hypothesis $\left(\mathrm{H}_{1}\right)$, the results showed that the firm pursuing common design by users is associated with higher innovation ability $\left(\mathrm{M}_{\text {Users }}=4.68\right)$ than the firm pursuing design by company designers $\left(\mathrm{M}_{\text {Designers }}=4.07 ; p<.01\right.$; see Table 2$)$. At the same time, and consistent with our theorization, however, the results also showed that users are perceived to have less expertise than professional designers even in a relatively simple design task such as designing cereal mixes $\left(\mathrm{M}_{\text {Users }}=\right.$ 3.96, $\left.\mathrm{M}_{\text {Designers }}=4.49 ; p<.05\right)$, which underscores the counterintuitive nature of the effect. To address alternative explanations for $\mathrm{H}_{1}$, we ran a model that included the perceived newness of the firm's business model and NPD salience as covariates. Although the data indicate that newness $(p<.05)$ (but not NPD salience $[p>.41]$ or expertise $[p>.42])$ is significantly related to innovation ability, the treatment effect remained significant after controlling for these alternative accounts $(p<.05)$. Thus, it is unlikely that the innovation effect of user design can be exclusively attributed to these alternative explanations.

Next, we found support for $\mathrm{H}_{5}$. The firm pursuing common design by users received greater reported purchase intentions $\left(\mathrm{M}_{\mathrm{Users}}=.24\right)$ than the firm pursuing design by company designers $\left(\mathrm{M}_{\text {Designers }}=-.21 ; p<.05\right)$. Adding innovation ability as a covariate to the model reduced the purchase-intention effect $(p<.10)$ and produced a significant effect of innovation ability on purchase intention $(p<$ .05). Bootstrap analyses (Preacher and Hayes 2008) further suggest that the effect of common design by users on purchase intention is mediated by innovation ability (bootstrap 95\% confidence interval $[\mathrm{CI}]: .02<\mathrm{CI}<.27$ ). The results are robust if we add our control variables as covariates to the model (95\% CI: .01/.23).

To test $\mathrm{H}_{3}$ (familiarity with user innovation as a moderator), we followed the procedures that Aiken and West (1993) suggest. For this analysis, we mean-centered the moderator variable and used effect coding for the design mode (where $-1=$ designers and $1=$ users). Including the interaction term between moderator and treatment in the second step of the analysis yielded a significant change in $\mathrm{R}$-square $(p<.05)$. Thus, we found a significant interaction effect $(\beta=.22, p<.05)$, in addition to a significant main effect of the design mode $(\beta=.31, p<.01)$. The positive direction of the interaction effect supports our prediction that the innovation effect of user design is positively related to consumers' general familiarity with user innovation (see 
TABLE 1

Measurement Items

\begin{tabular}{|c|c|}
\hline Con & Items \\
\hline ant & $\begin{array}{l}\text { /hat do you think about the firm's innovation ability? I think this company's ability to innovate is... (1) "not } \\
\text { ery high [1]/very high [7]," (2) "not very strong/very strong," and (3) "not excellent/excellent" (Luo and } \\
\text { hattacharya 2006)b }\end{array}$ \\
\hline $\begin{array}{l}\text { esign } \\
\text { expertisea }\end{array}$ & $\begin{array}{l}\text { In your opinion, how high is the design expertise of the people designing for this company? (1) "They have } \\
\text { very low [1]/They have very high design expertise [7]"; Do you think that the people designing for this com- } \\
\text { pany have the necessary skills (know-how) and competence to design new products? (2) "They don't have } \\
\text { the necessary skills [1]/They have the necessary skills [7]" (Ratneshwar and Chaiken 1991). }\end{array}$ \\
\hline wnessa & $\begin{array}{l}\text { How "new" do you perceive the company's business model, i.e., their way to develop new products? ("not } \\
\text { very new [1]/very new [7]") }\end{array}$ \\
\hline alience ${ }^{a}$ & $\begin{array}{l}\text { How much attention did you pay to the way the company develops new products? ("I have not thought about } \\
\text { it at all [1]/l have thought about it a lot [7]") }\end{array}$ \\
\hline $\begin{array}{l}\text { Familiarity } \\
\text { with user } \\
\text { innovationc }\end{array}$ & $\begin{array}{l}\text { (1) Have you ever invented a new use for a product that the manufacturer never intended? (2) Have you } \\
\text { ever developed a product yourself (either modifying an existing product or creating a new artifact from } \\
\text { scratch? (3) Do you personally know other people who have already developed a product themselves (either } \\
\text { modifying an existing product or creating a new artifact from scratch)? ( } 0=\text { no, and } 1=\text { yes) (Franke, Von } \\
\text { Hippel, and Schreier 2006) }\end{array}$ \\
\hline $\begin{array}{l}\text { Outcome } \\
\text { variable(s)a }\end{array}$ & $\begin{array}{l}\text { Please imagine that you would like to buy a product from this category. If you had the opportunity, would you } \\
\text { consider purchasing a product from this company? (1) I would seriously consider purchasing products from } \\
\text { this company; (2) I would actively search for this company (both items: } 1 \text { = "strongly disagree," and } 7= \\
\text { "strongly agree"); (3) To me, purchasing a product from this company is "very unlikely [1]/likely [7]," (4) "very } \\
\text { improbable [1]/very probable [7]"; (5) What would be the future purchase probability of products from this } \\
\text { company?" (vertical scale where } 0=\text { "no chance, would never buy," and } 10=\text { "certain, practically certain, } \\
\text { would definitely buy") (Bruner and Hensel 2001)d }\end{array}$ \\
\hline ers & $\begin{array}{l}\text { (1) I think that a lot of people design for this company; (2) I think that the company accumulates a very large } \\
\text { number of new T-shirt designs; (3) On average, I think this company can draw upon a lot of ideas for new T- } \\
\text { shirt designs. ( } 1 \text { = "strongly disagree," and } 7=\text { "strongly agree") }\end{array}$ \\
\hline $\begin{array}{l}\text { Divers } \\
\text { argu }\end{array}$ & $\begin{array}{l}\text { I think that the people designing for this company... (1)... are [not] very different from each other, (2) ...have } \\
\text { a very similar [dissimilar] background; (3) I think that the design ideas for new T-shirts are [not] very different } \\
\text { from each other. }(1 ; 7)\end{array}$ \\
\hline $\begin{array}{l}\text { User } \\
\text { argumente }\end{array}$ & $\begin{array}{l}\text { eds and prob- } \\
\text { 7) }\end{array}$ \\
\hline argl & $\begin{array}{l}\text { (1) I think that the designers do not have a lot of freedom in designing products; (2) When designing products, } \\
\text { I believe that company designers/users might [not] be constrained by some company requirements; (3) With } \\
\text { regard to new product design, I believe that designers/users [do not] need to follow specific design or marketing } \\
\text { conventions of the company. ( } 1 \text { = "strongly disagree," and } 7 \text { = "strongly agree") (Aiken and Hage 1966) }\end{array}$ \\
\hline \multicolumn{2}{|c|}{$\begin{array}{l}\text { aMeasured in Studies } 1-4 \text {. } \\
\text { bln Study } 3 \text {, we added the following scale measures: (1) I think the firm has the ability to develop really innovative new products, (2) The firm is } \\
\text { in the position to derive very original product ideas, (3) The company has a large potential to foster creativity, and (4) I think the firm can create } \\
\text { very interesting new products (cereal mixes) (1 = "strongly disagree," and } 7 \text { = "strongly agree"; adapted from Rindfleisch and Moorman } 2001 \text { ). } \\
\text { cMeasured in Study } 1 \text {. } \\
\text { dIn Study } 4 \text {, we used only items } 3 \text { and } 5 \text { (seven-point scales). In Study } 3 \text {, we used different outcome variables. We captured absolute WTP } \\
\text { (What is the maximum amount of money you want to spend for a package of cereals of Company A in this auction?) and recommendation } \\
\text { intent (How likely is it that you recommend this firm to a friend or a colleague? } 0 \text { = "completely unlikely," and } 10=\text { "extremely likely"; vertical } \\
\text { scale). In Study 2, we also measured recommendation intent with two different items (I would recommend this firm; I would talk up this firm to } \\
\text { my friends; } 1 \text { = "strongly disagree," and } 7 \text { = "strongly agree"; Bruner and Hensel 2001). } \\
\text { eMeasured in Study } 2 \text {. }\end{array}$} \\
\hline
\end{tabular}

Figure 2). Deconstructing the interaction at one standard deviation above and below the mean for familiarity revealed that the innovation effect of user design is significant for consumers with high familiarity $(\beta=.52, p<.001)$ but not for those with low familiarity $(\beta=.09, p>.58)$.

Overall, these findings support $\mathrm{H}_{3}$ : A consumer's familiarity with user innovation moderates the innovation effect of common design by users (i.e., for consumers with a respective low familiarity, the effect is attenuated). Recall that a rationale for $\mathrm{H}_{3}$ is that consumers with low familiarity scores are unable to make necessary attributions about common design by users. To gain some empirical insights into this conjecture, we separately regressed familiarity with user innovation on expertise of the people designing for the underlying company for both design modes. Then, we compared the regression coefficients using Chow's test for differences between coefficients drawn from independent subgroups (Chow 1960). The test reveals that the standardized regression coefficients were significantly higher in the user condition $(\beta=.37, p<.05)$ than in the designer condition $(\beta=.11, p>.50$; difference: $p<.05)$. Put differently, this indicates that familiarity with user innovation 
TABLE 2

Summary of Key Findings (Studies 1-4)

\begin{tabular}{|c|c|c|c|}
\hline & $\begin{array}{c}\text { Common Design } \\
\text { by Users (M) }\end{array}$ & $\begin{array}{l}\text { Design by Company } \\
\text { Designers (M) }\end{array}$ & Statistics \\
\hline \multicolumn{4}{|l|}{ Study 1 (Cereals) } \\
\hline Innovation ability & 4.68 & 4.07 & $\mathrm{~F}_{(1,78)}=7.86, p<.01, \eta_{p}^{2}=.09$ \\
\hline Expertise & 3.96 & 4.49 & $\mathrm{~F}_{(1,78)}=4.29, p=.04, \eta_{\mathrm{p}}^{2}=.05$ \\
\hline Purchase intent & .24 & -.21 & $\mathrm{~F}_{(1,78)}=6.59, p=.01, \eta_{p}^{2}=.08$ \\
\hline \multicolumn{4}{|l|}{ Study 2 (T-Shirts) } \\
\hline Innovation ability & 5.45 & 4.54 & $\mathrm{~F}_{(1,159)}=26.45, p<.001, \eta_{p}^{2}=.14$ \\
\hline Expertise & 4.46 & 4.85 & $\mathrm{~F}_{(1,159)}=3.67, p=.057, \eta_{\mathrm{p}}^{2}=.02$ \\
\hline Purchase intent & .21 & -.22 & $\mathrm{~F}_{(1,159)}=10.73, p<.001, \eta_{\mathrm{p}}^{2}=.06$ \\
\hline Recommendation intent & 4.93 & 3.88 & $\mathrm{~F}_{(1,159)}=18.91, p<.001, \eta_{\mathrm{p}}^{2}=.11$ \\
\hline Numbers argument & 5.54 & 4.40 & $\mathrm{~F}_{(1,159)}=30.10, p<.001, \eta_{\mathrm{p}}^{2}=.16$ \\
\hline Diversity argument & 5.02 & 3.99 & $\mathrm{~F}_{(1,159)}=23.83, p<.001, \eta_{\mathrm{p}}^{2}=.13$ \\
\hline User argument & 5.27 & 4.41 & $\mathrm{~F}_{(1,159)}=18.35, p<.001, \eta_{\mathrm{p}}^{2}=.10$ \\
\hline Constraints argument & 3.67 & 4.21 & $\mathrm{~F}_{(1,159)}=6.76, p \leq .01, \eta_{p}^{2}=.04$ \\
\hline \multicolumn{4}{|l|}{ Study 3 (Cereals) } \\
\hline Innovation ability & 4.92 & 4.50 & $\mathrm{~F}_{(1,402)}=10.48, p=.001, \eta_{\mathrm{p}}^{2}=.03$ \\
\hline Expertise & 4.60 & 5.01 & $\mathrm{~F}_{(1,402)}=10.24, p=.001, \eta_{\mathrm{p}}^{2}=.03$ \\
\hline WTP in Euros & 12.28 & 8.09 & $\mathrm{~F}_{(1,402)}=6.44, p=.012, \eta_{p}^{2}=.02$ \\
\hline Recommendation intent & 4.92 & 4.23 & $\mathrm{~F}_{(1,402)}=7.68, p=.006, \eta_{p}^{2}=.02$ \\
\hline \multicolumn{4}{|c|}{ Study 4 (Product Replicates) } \\
\hline \multicolumn{4}{|l|}{ Low-complexity products } \\
\hline Innovation abilitya & 4.76 & 3.94 & $\mathrm{~F}_{(1,95)}=17.23, p<.001, \eta_{p}^{2}=.15$ \\
\hline Expertise & 4.21 & 4.83 & $\mathrm{~F}_{(1,95)}=6.20, p<.05, \eta_{\mathrm{p}}^{2}=.06$ \\
\hline Purchase intentb & 4.64 & 4.07 & $\mathrm{~F}_{(1,95)}=7.21, p<.01, \eta_{p}^{2}=.07$ \\
\hline \multicolumn{4}{|l|}{ High-complexity products } \\
\hline Innovation abilityc & 4.68 & 4.89 & $\mathrm{~F}_{(1,95)}=1.17, p=.28, \eta_{\mathrm{p}}^{2}=.01$ \\
\hline Expertise & 4.24 & 5.32 & $\mathrm{~F}_{(1,95)}=19.64, p<.001, \eta_{\mathrm{p}}^{2}=.17$ \\
\hline Purchase intentd & 4.54 & 4.75 & $\mathrm{~F}_{(1,95)}=1.03, p=.31, \eta_{\mathrm{p}}^{2}=.01$ \\
\hline
\end{tabular}

aReplicates: T-shirts: $M_{U s e r s}=4.47, M_{\text {Designers }}=3.52$; household: $M_{U s e r s}=4.86, M_{\text {Designers }}=4.09 ;$ sports: $M_{U s e r s}=4.94, M_{\text {Designers }}=4.21$.

bReplicates: T-shirts: $M_{\text {Users }}=4.39, M_{\text {Designers }}=3.89$; household: $M_{U s e r s}=4.75, M_{\text {Designers }}=4.24 ;$ sports: $M_{U s e r s}=4.77, M_{\text {Designers }}=4.09$.

cReplicates: Electronics: $M_{\text {Users }}=4.51, M_{\text {Designers }}=5.00$; gardening: $M_{\text {Users }}=4.78, M_{\text {Designers }}=4.90 ;$ robots: $M_{\text {Users }}=4.77, M_{\text {Designers }}=4.78$.

dReplicates: Electronics: $M_{\text {Users }}=4.26, M_{\text {Designers }}=4.22$; gardening: $M_{\text {Users }}=4.80, M_{\text {Designers }}=5.00 ;$ robots: $M_{\text {Users }}=4.57, M_{\text {Designers }}=5.04$.

affects the extent to which users (but not designers) are perceived to have design expertise. This finding provides convergent evidence for our proposed framework.

In summary, Study 1 provides strong evidence for the innovation effect of common design by users $\left(\mathrm{H}_{1}\right)$. We also addressed important alternate explanations and highlighted the relevance of our focal variable, innovation ability, by demonstrating that it mediates main effects on purchase intentions $\left(\mathrm{H}_{5}\right)$. Furthermore, we demonstrated a first boundary condition of the effect: It is attenuated if consumers are not familiar with user innovation $\left(\mathrm{H}_{3}\right)$.

\section{Study 2}

\section{Overview and Method}

In Study 2, we attempted to understand why consumers perceive companies that use common design by users to produce more innovative products $\left(\mathrm{H}_{2}\right)$. We followed the procedure used in Study 1, with a few noted exceptions. First, instead of using a student sample, we collected data from an online consumer panel. Second, we used T-shirts as the underlying product category to study. Participants consisted of 161 consumers $\left(\mathrm{M}_{\mathrm{age}}=29\right.$ years, $\mathrm{SD}=6 ; 52 \%$ female $)$ randomly assigned to one of two experimental groups (common design by users vs. design by company designers). After treatment, participants completed a questionnaire that included measures for the four characteristics of common design by users, innovation ability, purchase intent, and-as an additional, managerially relevant outcome variable-consumers' intention to recommend the firm to others. Again, we counterbalanced the order of the item blocks for innovation ability and for the downstream variables. In addition, we counterbalanced the order of the four explanatory variables (before or after innovation ability). Finally, we captured our three control variables (newness, NPD salience, and expertise).

We used the same scales to measure perceived innovation ability $(\alpha=.93)$, purchase intentions $(\alpha=.91)$, expertise $(\alpha=.79)$, and the other control variables as in Study 1 . We measured the numbers argument with three items (e.g., "I think that a lot of people design for this company," $\alpha=$ .90), the diversity argument with three items (e.g., "I think that the people designing for this company have a very 
FIGURE 2

Familiarity with User Innovation $\times$ Design Mode Interaction (Study 1)

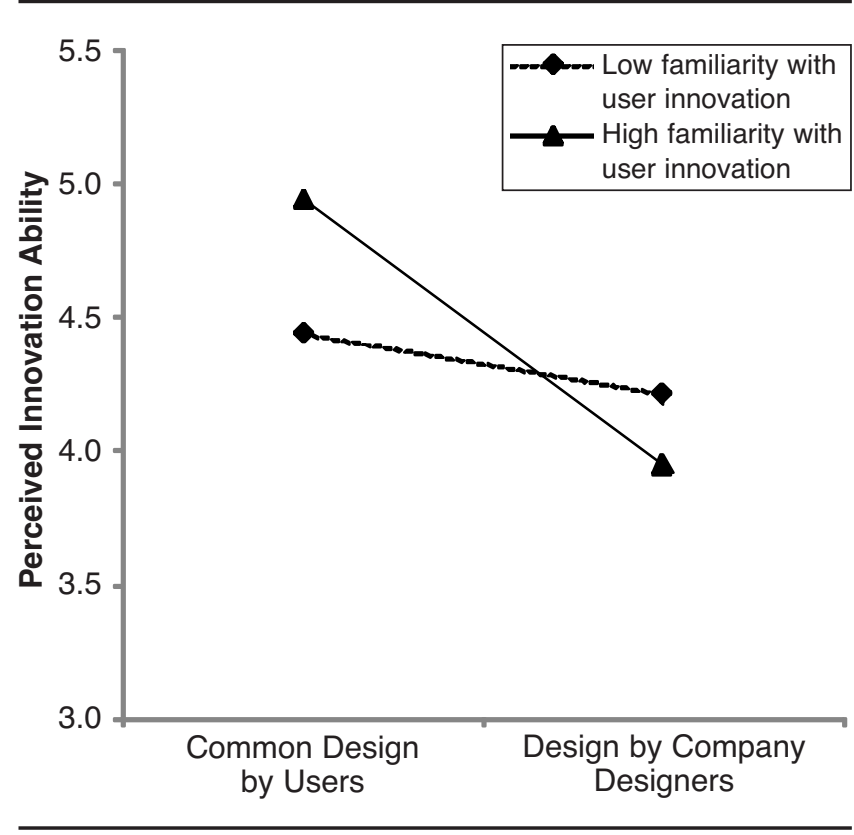

similar [dissimilar] background," $\alpha=.86$ ), the user argument with two items (e.g., "I think that the people designing for this company [do not] exactly know the specific needs and problems of consumers," $\alpha=.69$ ), and the constraints argument with three items (e.g., "I think that the designers do not have a lot of freedom in designing products," $\alpha=$ .79). Finally, we captured recommendation with two items (e.g., "I would recommend this firm," $\alpha=.92$ ). For full measures, see Table 1.

\section{Findings}

Preliminary analyses. First, it was important to assess discriminant validity of the four defining characteristics of common design by users and innovation ability. Following extant literature (see DeVellis 2003; Zhao, Lynch, and Chen 2010 , p. 205), we conducted a series of confirmatory factor analyses. The results suggest that all five variables are empirically distinct. ${ }^{3}$

\footnotetext{
${ }^{3}$ Regarding the four defining characteristics of common design by users, we compared the fit of our proposed four-factor model with various combinations of reduced factor models (e.g., a onefactor model, any combinations of two-factor models). The fit of the four-factor model is significantly better than any reduced factor model $\left(\Delta \mathrm{s} \chi^{2}>20.47, p s<.001\right)$. We also applied the same logic to our proposed five-factor model (including innovation ability). Again, the five-factor model produces a significantly better fit than any reduced model $\left(\Delta \mathrm{s} \chi^{2}>34.38, p \mathrm{~s}<.001\right)$. As a complementary test, we compared the average variance extracted (AVE) of each of the five constructs with the squared interconstruct correlations and find throughout that each pair of squared interconstruct correlations is lower than the respective AVE (Fornell and Larcker 1981). Taken together, these results provide strong evidence for discriminant validity. Moreover, all factor loadings were significant and exceeded .67; the AVEs were higher than the recommended .50 benchmark (Fornell and Larcker 1981).
}

Primary analyses. In line with $\mathrm{H}_{2}$, we found four main effects on the defining characteristics (see Table 2). If the firm is described as pursuing common design by users, participants assign higher scores for the numbers $\left(\mathrm{M}_{\text {Users }}=\right.$ 5.54 vs. $\left.\mathrm{M}_{\text {Designers }}=4.40 ; p<.001\right)$, diversity $\left(\mathrm{M}_{\text {Users }}=\right.$ 5.02 vs. $\left.\mathrm{M}_{\text {Designers }}=3.99 ; p<.001\right)$, and user $\left(\mathrm{M}_{\text {Users }}=5.27\right.$ vs. $\left.\mathrm{M}_{\text {Designers }}=4.41 ; p<.001\right)$ arguments and accordingly lower scores for the constraints argument $\left(\mathrm{M}_{\mathrm{Users}}=3.67 \mathrm{vs}\right.$. $\left.\mathrm{M}_{\text {Designers }}=4.21 ; p \leq .01\right)$.

Second, we also replicated the innovation effect of user design (innovation ability: $\mathrm{M}_{\text {Users }}=5.45$ vs. $\mathrm{M}_{\text {Designers }}=$ $4.54 ; p<.001)$, despite a negative expertise effect $\left(\mathrm{M}_{\mathrm{Users}}=\right.$ $\left.4.46, \mathrm{M}_{\text {Designers }}=4.85 ; p=.05\right)$. As in Study 1 , we ran the model with innovation ability as the dependent variable while controlling for newness and NPD salience. Although newness $(p<.01)$, NPD salience $(p<.01)$, and expertise $(p<$ $.05)$ are significantly related to innovation ability, the treatment effect again remains highly significant after controlling for these variables $(p<.001)$.

Third, including the defining characteristics as covariates to the model reveals significant main effects of the numbers $(p<.01)$, diversity $(p<.05)$, user $(p<.01)$, and constraints $(p<.05)$ arguments - while, importantly, the main effect of the design mode becomes insignificant $(p>$ .27). Moreover, a bootstrap analysis that simultaneously included the numbers, diversity, user, and constraints arguments revealed that taken together, they mediate the path between design mode and innovation ability (CI 95\%: .50/ 1.04).

Finally, we also identified main effects on our downstream variables. An analysis of variance (ANOVA) reveals that the user condition scores significantly higher on purchase and recommendation intentions than the designer condition (purchase intent: $\mathrm{M}_{\mathrm{User}}=.21, \mathrm{M}_{\text {Designer }}=-.22 ; p<$ .001 ; recommendation intent: $\mathrm{M}_{\mathrm{User}}=4.93, \mathrm{M}_{\text {Designer }}=$ $3.88 ; p<.001)$. This effect disappears if we add innovation ability to the model ( $p s>.15)$. At the same time, the main effect of innovation ability is highly significant $(p s<.001)$, which indicates that innovation ability mediates the direct path of common design by users on behavioral intentions. Bootstrap analysis confirms mediation (CI 99\%: purchase intent: .18/.62; recommendation intent: .49/1.11).

\section{Discussion}

In summary, Study 2 replicates the main findings obtained in the first study. Most important, in support of $\mathrm{H}_{2}$, it also suggests that the defining characteristics of common design by users (i.e., the number, diversity, user, and constraints arguments) fully account for the innovation effect of user design observed. Although this study provides sound evidence for the treatment characteristic effects, causal definition from each of the characteristics on innovation ability cannot be claimed (due to the correlational structure of the data). However, such a test could be done by manipulating the characteristics in addition to the design mode (e.g., Spencer, Zanna, and Fong 2005; Zhao, Lynch, and Chen 2010).

Although we believe that our main study is superior to such a procedure for our purpose (we needed to establish 
the treatment-characteristic relationship, which is not possible by this alternative procedure), we conducted an add-on study to address this limitation. In summary, a set of five additional experiments provide convergent evidence that each of the four variables causally adds an incremental explanation of the innovation effect of user design. Importantly, findings show that if all four characteristics between the two design mode conditions are held experimentally constant, consumers do perceive both firms to have similar innovation abilities. The Web Appendix provides a more detailed summary of this add-on study (www.marketingpower.com/ jm_webappendix).

\section{Study 3}

\section{Overview and Method}

Study 3 has three objectives. First, we sought to replicate the innovation effect of user design using stimuli that is closer to the point-of-purchase (i.e., incorporating the treatment in the product's packaging). Second, we aimed to come closer to measuring actual behavior (instead of purchase intent) by assessing consumers' willingness to pay (WTP). Third, it could be argued that our theory only holds for product innovation centered on aspects of aesthetic product design (e.g., a new cereal with a better taste or look) but not for more functional elements of product design (e.g., a cereal with better health or nutritional functions). The experimental setup was modified accordingly to test this potential limitation of the innovation effect of user design.

Thus, we used a 2 (common design by users vs. design by company designers) $\times 2$ (innovation focus: aesthetics vs functions) between-subjects design. Four hundred six consumers $\left(M_{\text {age }}=28\right.$ years, ranging from 19 to 55 years; $62 \%$ female) recruited from a professional market research agency participated in this online study. Participants were exposed to a picture of a cereal package that varied along the two experimental factors. The design mode manipulation on the packaging followed Study 1. We achieved the innovation focus manipulation by positioning the cereal as intended to attract customers either by being tastier (aesthetics) or by having better health effects (functions) (see the Appendix).

After inspecting the packaging, participants completed a short questionnaire (see Table 1). We measured innovation ability using two approaches. First, we used a new fouritem Likert-type scale to determine whether our previous findings are robust to the construct's operationalization (the new measure used more fine-grained rating scales voiced from the perspective of the customer; e.g., "I think the firm has the ability to develop really innovative new products"; $\alpha=.92)$. This was followed by the same global measures we employed in Study $1(\alpha=.95)$. The two measures were highly correlated $(\mathrm{r}=.75, p<.001)$ and a confirmatory factor analysis revealed a single factor with all loadings exceeding .75. Therefore, we combined both scale measures to form an innovation index (the findings reported here are parallel if only one of the two measures is employed).

We measured willingness to pay (WTP) in an openended format using a Vickrey fifth-price auction procedure (e.g., Hoffman et al. 1993; Vickrey 1961) coupled with the incentive-aligned mechanism that Ding (2007) proposes. Specifically, participants were informed that a raffle for $€ 100$ would be held at the end of the study (this amount served as an incentive to indicate participants' actual WTP). If they won the prize, they were told, their WTP for the cereal would be binding. In particular, they were informed that if they won the $€ 100$ and if their bid was (not) among the four highest bids, they would (not) have purchased a package of cereals of Company A. The price to be paid would be equal to the fifth-highest bid (Hoffman et al. 1993). This auction procedure combines economic incentive alignment (see Ding 2007) with our study constraints. (The underlying product did not exist, so we were not allowed to sell products to study participants on a systematic basis.) The WTP measure followed the preamble: "What is the maximum amount of money you are ready to spend for a package of cereals of Company A in this auction?"

This outcome measure was complemented by a tenpoint vertical scale capturing consumers' intent to recommend the firm's products to others. Again, we counterbalanced the order of innovation ability and outcome variables. Finally, we used the same scales to measure our control variables (newness, NPD salience, and expertise [ $\alpha=.84]$ ), and as a manipulation check, we asked participants to what extent they agreed with the following items: (1) "With its cereals, this company focuses on functionality (the main focus is on improving well-being and performance)," and (2) "With its cereals, this company focuses on taste (the main focus is on better flavor and more taste)" (1 = "strongly disagree," and 7 = "strongly agree").

\section{Findings and Discussion}

Manipulation check. As we expected, a $2 \times 2$ ANOVA revealed that consumers in the aesthetic condition perceived the firm to focus more/less on taste/functionality $(\mathrm{M}=$ $4.86 / \mathrm{M}=3.61)$ than in the functional condition $(\mathrm{M}=3.42$ / $\mathrm{M}=5.72 ; p \mathrm{~s}<.001)$. There were no other significant effects $(p s>.24)$. The findings indicate that our manipulation was successful.

Main analyses. A $2 \times 2$ ANOVA on innovation ability reveals a significant main effect of the design mode $(p<.01)$. Again, the firm pursuing common design by users was associated with higher innovation ability $\left(\mathrm{M}_{\text {User }}=4.92\right)$ than the firm pursuing design by company designers $\left(\mathrm{M}_{\text {Designer }}=\right.$ 4.50). Importantly, the main effect of the second factor and the interaction were insignificant ( $p s>.60)$. Thus, the innovation effect of user design appears to have applicability whether the innovation focus lies in aesthetics or in functionality. Moreover, the innovation effect of user design remained highly significant when we added newness $(p<.001)$, NPD salience $(p<.05)$, and expertise $(p<.001)$ as covariates to the model $(p<.001)$. Again, we identified a negative expertise effect $\left(\mathrm{M}_{\text {Users }}=4.60, \mathrm{M}_{\text {Designers }}=5.01 ; p=.001\right.$; other $\left.p \mathrm{~s}>.87\right)$.

A $2 \times 2$ ANOVA on the WTP measure also yields a significant effect of the design mode factor $(p=.01)$ : Consumers' WTP is shown to be substantially higher for products of firms that foster common design by users $\left(\mathrm{M}_{\mathrm{User}}=\right.$ $12.28)$ versus professional designers $\left(M_{\text {Designer }}=8.09\right)$. The 
interaction between the two experimental factors is again not significant $(p>.28)$, though consumers tend to be willing to pay more for the cereal if they were in the tasty versus functional cereal condition $\left(\mathrm{M}_{\text {Taste }}=11.59, \mathrm{M}_{\text {Functionality }}=8.74\right.$; $p=.07)$. Bootstrap analysis demonstrates that innovation ability helps explain this WTP effect (CI 90\%: .04/1.31). Furthermore, our results show that common design by users also directly affects consumers' recommendation intent $\left(\mathrm{M}_{\mathrm{User}}=4.92, \mathrm{M}_{\text {Designer }}=4.23 ; p<.01\right.$; other $\left.p \mathrm{~s}>.67\right)$. Once again, this effect is mediated by higher innovation ability perceptions (99\%: .12/.86).

In summary, this study significantly complements our previous results. Most important, we observed the innovation effect of user design in a setting that is closer to the point of purchase (manipulation of product packaging), it has a significant effect on consumers' WTP as well as recommendation intentions, and this effect holds for design innovations aimed at functionally new products as well as for aesthetic product changes.

\section{Study 4}

\section{Overview and Method}

Study 4 has two objectives. First, we aimed to replicate $\mathrm{H}_{1}$ in different product categories. Second, we sought to test our second boundary condition: product complexity $\left(\mathrm{H}_{4}\right)$. We adopted a 2 (common design by users vs. design by company designers $) \times 2$ (product complexity: low vs. high) $\times 3$ (product replicates) design, in which the first two factors are between-subjects and the third is a within-subject factor. T-shirts, household products, and outdoor sports equipment represented low-complexity consumer products, whereas consumer electronics, electric/mechanical gardening products, and robotic toys represented high-complexity consumer products. We based product selection on examples from practice (1) in which firms were already drawing on users in product design or (2) in which users are frequently observed to innovate (e.g., Von Hippel, De Jong, and Flowers 2012).

We pretested perceived product complexity using an independent sample of 26 students. The results confirmed expectations: T-shirts, household products, and outdoor sports equipment can be qualified as low-complexity products, similar to cereal mixes (Studies 1 and 3), and they are perceived as much less complex to design than consumer electronics, electric/mechanical gardening products, and robotic toys, which can be qualified as high-complexity products. 4

\footnotetext{
4Participants rated each product category (exemplified by pictures) presented in random order on a nine-point scale where $1=$ "not complex at all to design" and $9=$ "very complex to design." Consistent with our expectations, we found low scores for lowcomplexity products $\left(\mathrm{M}_{\mathrm{T} \text {-shirts }}=3.17, \mathrm{M}_{\text {Household }}=3.74, \mathrm{M}_{\text {Sports }}=\right.$ $\left.4.29, \mathrm{M}_{\text {Cereals }}=3.09\right)$ and high scores for high-complexity products $\left(\mathrm{M}_{\text {Electronics }}=6.51, \mathrm{M}_{\text {Gardening }}=6.48, \mathrm{M}_{\text {Robots }}=6.83\right)$. A repeated measures ANOVA with two within-subject factors (two complexity levels; three product category levels) confirms that the difference between the low- and high-complexity products is highly significant $\left(\mathrm{M}_{\text {Low-complexity }}=3.73, \mathrm{M}_{\text {High complex }}=6.60 ; \Delta=\right.$ $2.87 ; p<.001)$ and substantially larger than the respective differences between the product categories within the complexity factor (average $\Delta_{\text {High complex }}=.25$, average $\Delta_{\text {Low-complexity }}=.74$ ).
}

Ninety-nine students participated in the main study (43\% female) and were randomly assigned to one of the four between-subjects groups. We counterbalanced the order of presentation of the within-subject product replicates. We used the same descriptions used in Study 1 (description of common design by users vs. company professionals). Because product replicates is a within-subject factor, we described the three firms jointly before participants were exposed to the exemplary products for each firm in sequence. Participants completed the respective questionnaire directly after having seen product pictures of one firm, after which they proceeded to the next picture/questionnaire.

We measured innovation ability as in Study $1(\alpha=.91)$. We also captured participants' purchase intention for a product of the underlying firms. Because of the within-subject nature of the study, we measured purchase intent with an abridged index consisting of two items $(\alpha=.83$; see Table 1$)$. Again, we counterbalanced the order of these two variables. At the end of the questionnaire, we measured the control variables (newness, NPD salience, and expertise $[\alpha=.73]$ ).

\section{Findings and Discussion}

Preliminary analyses. To justify collapsing across product replicates, we first tested whether the individual variation in products interacted with the manipulated factors (for means, see Table 2). The results revealed that for both innovation ability and purchase intention, the three-way interaction and the two-way interactions with the product factor proved insignificant ( $p$ s $>.58$ ), enabling us to collapse across the replicate factor.

Primary analyses. We conducted a 2 (users vs. designers) $\times 2$ (low vs. high complexity) ANOVA with perceived innovation ability as the dependent variable. First, we identified a significant main effect of complexity $\left(p<.01 ; \mathrm{M}_{\text {Low }}\right.$ complexity $=4.35, \mathrm{M}_{\text {High complexity }}=4.79$ ) and a significant effect of the design mode $\left(p<.05 ; \mathrm{M}_{\text {Users }}=4.72, \mathrm{M}_{\text {Designers }}=\right.$ 4.42). Most important, there was also a significant interaction between design mode and complexity $(p<.001$; see Figure $3)$. Decomposing the interaction by complexity revealed that consistent with our prediction $\left(\mathrm{H}_{4}\right)$, the innovation effect of user design is replicated for the low-complexity products $\left(\mathrm{M}_{\mathrm{Users}}=4.76, \mathrm{M}_{\text {Designers }}=3.94 ; p<.001\right)$, but it is attenuated in the high-complexity condition $\left(\mathrm{M}_{\mathrm{User}}=\right.$ $\left.4.68, \mathrm{M}_{\text {Designer }}=4.89 ; p>.28\right)$. The results are robust if the control variables newness $(p s>.35)$, NPD salience $\left(p_{\text {Low }}\right.$ complexity $\left.<.10, p_{\text {High complexity }}>.53\right)$, and expertise $(p s<$ $.05)$ are entered as covariates into the model $\left(p_{\text {Interaction }}=\right.$ $.001, p_{\text {Low complexity }}<.001, p_{\text {High complexity }}>.57$ ).

To explore the mechanism underlying $\mathrm{H}_{4}$ in more detail, we subjected perceived expertise of the people designing for the underlying firms to the $2 \times 2$ ANOVA. We identified a strong effect of the design mode $\left(\mathrm{M}_{\text {Users }}=4.22, \mathrm{M}_{\text {Designers }}=\right.$ 5.07; $p<.001)$ and an insignificant effect of complexity $(p>$ .13). Although the effect size of the expertise gap between users and designers tends to increase with complexity (low complexity: $\mathrm{M}_{\text {Users }}=4.21, \mathrm{M}_{\text {Designers }}=4.83 ; p<.05, \eta_{\mathrm{p}}^{2}=$ .06 ; high complexity: $\mathrm{M}_{\mathrm{User}}=4.24 ; \mathrm{M}_{\text {Designer }}=5.32 ; p<$ $\left..001, \eta_{\mathrm{p}}^{2}=.17\right)$, the interaction proved insignificant $(p>$ $.17)$. To further investigate the impact of expertise on inno- 
FIGURE 3 Complexity $\times$ Design Mode Interaction (Study 4)

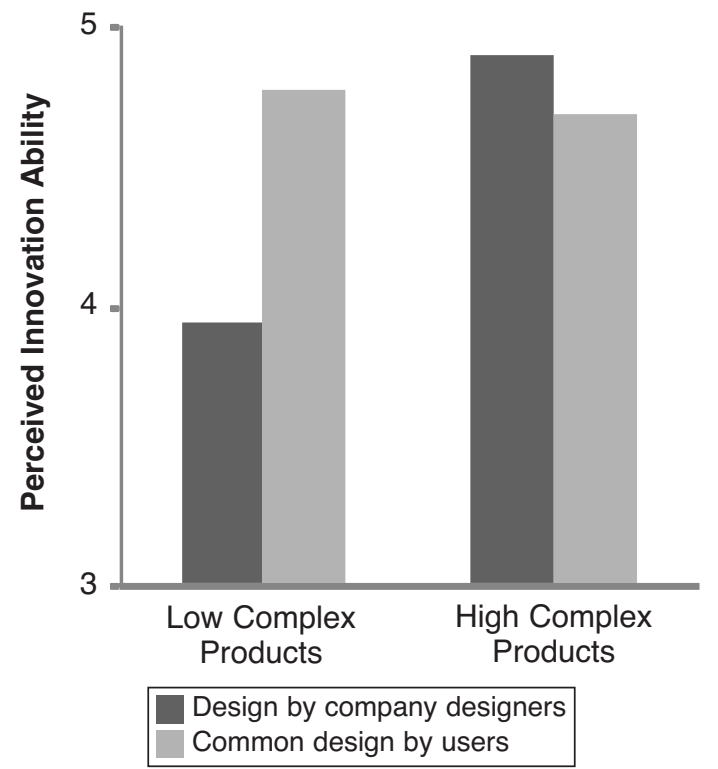

vation ability, we regressed innovation ability on expertise for both complexity conditions. The results are consistent with our theorization: The respective regression coefficient is significantly lower in the low-complexity condition $(\beta=$ $.10, p>.50)$ than in the high-complexity condition $(\beta=.40$, $p<.01$; Chow test results: $p<.01$ ). This result indicates that even if the expertise gap is not significantly higher for high-complexity products, the respective impact on innovation ability looms significantly larger, thereby attenuating the innovation effect of user design.

Finally, we ran a $2 \times 2$ ANOVA with purchase intent as the dependent variable. We identified a significant main effect of complexity $\left(\mathrm{M}_{\text {Low complexity }}=4.35, \mathrm{M}_{\text {High complexity }}=\right.$ $4.65 ; p<.05)$ and an insignificant effect of the design mode $(p>.23)$. However, consistent with our findings obtained previously, there is a significant complexity $\times$ design mode interaction $(p=.01)$. Follow-up contrasts reveal a significant positive effect of common design by users on purchase intentions in the low-complexity condition $\left(\mathrm{M}_{\text {Users }}=4.64\right.$, $\mathrm{M}_{\text {Designers }}=4.07 ; p<.01$ ) but not in the high-complexity condition $\left(\mathrm{M}_{\mathrm{Users}}=4.54, \mathrm{M}_{\text {Designers }}=4.75, p>.30\right)$. Adding innovation ability as a covariate to the model for the lowcomplexity condition reduces the purchase intention effect $(p>.16)$ and produces a positive effect of innovation ability on purchase intention $(p<.10)$. Bootstrap analyses further confirm that the effect of common design by users on purchase intention is mediated by innovation ability (90\% CI: $.01<\mathrm{CI}<.47)$. This again supports $\mathrm{H}_{5}$.

In summary, Study 4 replicates the innovation effect for user design in different product categories, but it also highlights that the effect is likely to hold only in low-complexity product categories. In contrast, for high-complexity products, the effect is attenuated. Although there were no interactions regarding within-subject replicates for high-complexity products, it is at least noteworthy that for consumer electronics (and to a lesser extent for electric/mechanical gardening products), the innovation effect of user design directionally reversed (Table 2). This result highlights that some consumer product categories might be too complex for consumers to perceive users as able to provide meaningful input, leading to a reversal rather than a mere attenuation of the innovation effect.

\section{General Discussion}

Companies such as Muji, LEGO, Threadless, and Quirky and other firms in a variety of consumer-goods fields have begun to complement or even substitute internal design teams with their user communities. As a result, talented users rather than firm professionals are now the designers of common products these firms market to consumers. The innovation literature has supported the "objective" promise of such user-driven companies (i.e., better products might be generated; see Von Hippel 2005). However, researchers have largely disregarded the more subtle reactions of nonparticipating consumers, who constitute the broader market (Fuchs and Schreier 2011). Little attention has been paid to how consumers perceive firms that encourage common design by users. This is important from a theoretical and substantive perspective, because this could affect consumer behavior beyond any concrete products such firms offer. As such, a better understanding of how the users' new roles in the value chain affect the market is essential (Moreau and Herd 2010).

\section{Theoretical Contributions}

Against this backdrop, we contribute to this emerging literature by exploring consumers' perceptions of companies selling products "designed by users." The primary focus of our research is on innovation ability inferences (i.e., perceptions of a company's ability to generate innovative products). Four studies provide firm evidence that common design by users enhances consumer perceptions of the firm's innovation ability - a counterintuitive effect given that consumers tend to assign less expertise to users than to company designers. We identify this innovation effect of user design across several product categories, including breakfast cereals, apparel, household products, and sports products.

This innovation inference can be understood in the context of four distinct variables that, taken together, define the fundamental difference of common design by users compared with more traditional design modes: (1) a numbers argument (more people involved leads to more ideas), (2) a diversity argument (more diverse people involved leads to more diverse ideas), (3) a user argument (actual users leads to more applicable ideas), and (4) a constraints argument (less constraint on people leads to more freedom in ideas). Moreover, we underscore the relevance of our focal variable, perceived innovation ability, because it explains main effects from common design by users on important outcome variables, including purchase intentions, willingness to pay, and consumers' intention to recommend the firm to others. Importantly, the innovation effect of user design for both functional and aesthetic design tasks is validated. 
Finally, we identify two important boundary condition variables. First, we find that even for relatively simple design tasks, the innovation effect of user design depends on consumers' familiarity with user innovation - the extent to which they had already had ideas for modifying existing products themselves or whether they know peers who had created their own user innovations. It seems that in the case of low familiarity, consumers do not have the "right" users in mind, attenuating the innovation effect of user design. Second, we demonstrate that product complexity plays an important role in the realization of this innovation effect. In particular, common design by users loses its perceived (vs. any "objective") power when the underlying design task becomes too complicated to be addressed effectively by users (e.g., robotic toys, consumer electronics, more complex gardening tools).

\section{Substantive Implications}

Our findings have important implications. First, they suggest that managers should consider consumers' specific firm perceptions - in particular, regarding higher innovation ability through user design - because these perceptions are likely to provide an additional explanation of why consumers are so enthusiastic about buying products from those firms (Threadless, for example, sells an average of 100,000 T-shirts per month). Managers should use this differentiating characteristic in positioning firms that employ common design by users vis-à-vis traditional competitors.

Our insights regarding the defining characteristics provide further guidance. Because these characteristics are related to innovation perceptions, managers should stress these cues in marketing them on the firm's website and in other communication activities. For example, managers should highlight the number of submitting users or the number of submitted designs; describe not only the diversity and background but also the expertise of participating users; and add user profiles that stress that they have talent, but they are also users just like the mass of consumers. All these tactics can boost innovation ability perceptions. Our finding that customers were willing to pay $50 \%$ more for a user-driven firm's products and that they are more eager to recommend the firm to others highlights that such efforts might pay off. If managers are successful in activating the right cues among consumers, they might benefit from an increase in demand-independent of the specific "objective" promise of their products.

Finally, our findings regarding the boundary condition variables can help managers predict for (1) what type of product and (2) what type of customer common design by users might bring about a positive user innovation inference and, through this, more favorable consumer behavior. Furthermore, it is important that managers understand consumer perceptions of the complexity of their underlying product. If the underlying design task is perceived as too complex, managers should probably not stress that products have been designed by users in campaigns aimed at reaching broader parts of the market.

This is because directionally, we find that for complex products such as consumer electronics and high-tech gar- dening tools, the innovation effect of user design tends to reverse. Although some firms (e.g., Sparkfun electronics, Arduino, Lasersaur, Open Source Ecology) have successfully employed common design by users in such categories, managers should be careful in advertising this tactic broadly because it could backfire. (Consumers might perceive these products as being already too complex for users to be able to provide meaningful input, leading to lower innovation ability perceptions, which might ultimately affect sales negatively.) Alternatively, managers might adapt the specific message to be communicated to consumers. Although stressing users' expertise might be less impactful for simple products such as cereals, it might be significantly more impactful for more complex products.

Consumers' familiarity with user innovation, our second moderator variable, also points to actionable implications. First, managers might use this variable as a positioning tool that would be stressed in the firm's communication efforts (e.g., "we all know that many users have creative ideas and often innovate for themselves"). This might help less familiar consumers get the "right" users on their radar when forming an impression of the firm. Finally, positioning common design by users to consumers familiar with user innovation might have an additional, favorable side effect of interest to managers. In addition to successfully marketing products designed by users to them, this process is likely to fuel positive word of mouth and accelerate the diffusion to other consumer groups. Indeed, research on user innovation and lead users shows that innovating users often serve other consumers as strong opinion leaders (e.g., Morrison, Roberts, and Midgley 2004; Schreier, Oberhauser, and Prüg1 2007).

\section{Limitations and Further Research}

There are two important limitations that warrant discussion and provide opportunities for further research. First, while our studies account for one potential difference in "observing" consumers (familiarity with user innovation), it seems plausible that common design by users might be perceived differently because of other individual differences. Indeed, the magnitude (and possibly also the direction) of the innovation effect of user design might depend on certain other consumer characteristics. One such moderator might be the consumers' involvement or expertise in the underlying domain. For example, avid consumers with a strong basis of knowledge about usage and technologies might recognize other competent users or perceive the underlying design task as less complex. In turn, this might enhance the innovation ability perceived in common design by users - possibly even for more complex product categories. Similarly, consumers' general skepticism toward companies (Barksdale and Darden 1982; higher levels of skepticism leads to more trust in users) and their locus of control (Rotter 1966; higher locus of control leads to more trust in users) might constitute two additional moderating variables.

Second, all our studies were based on a black-and-white comparison-contrasting only the extremes of the common design continuum with regard to the roles played by professional designers and users. However, in practice, many firms might find themselves somewhere in between (profes- 
sional designers co-creating value with leading-edge users). From a practical perspective, it might be worthwhile to explore consumer perceptions across the full design continuum, particularly in situations in which users are perceived to have substantially less expertise than designers or the underlying product is characterized by high levels of complexity. For such categories, for example, a hybrid design mode may be perceived as superior to both extremes because it combines the potential advantages of both ends of the spectrum - namely, tapping users as a creative source of ideas and converting the best ideas into useful products with professional excellence in NPD and design. However, this is speculative and calls for further investigation. Taking up these and related issues will help build a more complete theory, which will address the consequences of the new roles users play in the product design process.

\section{APPENDIX Stimuli for Study 3}

(Example: common design by users; functional cereal)

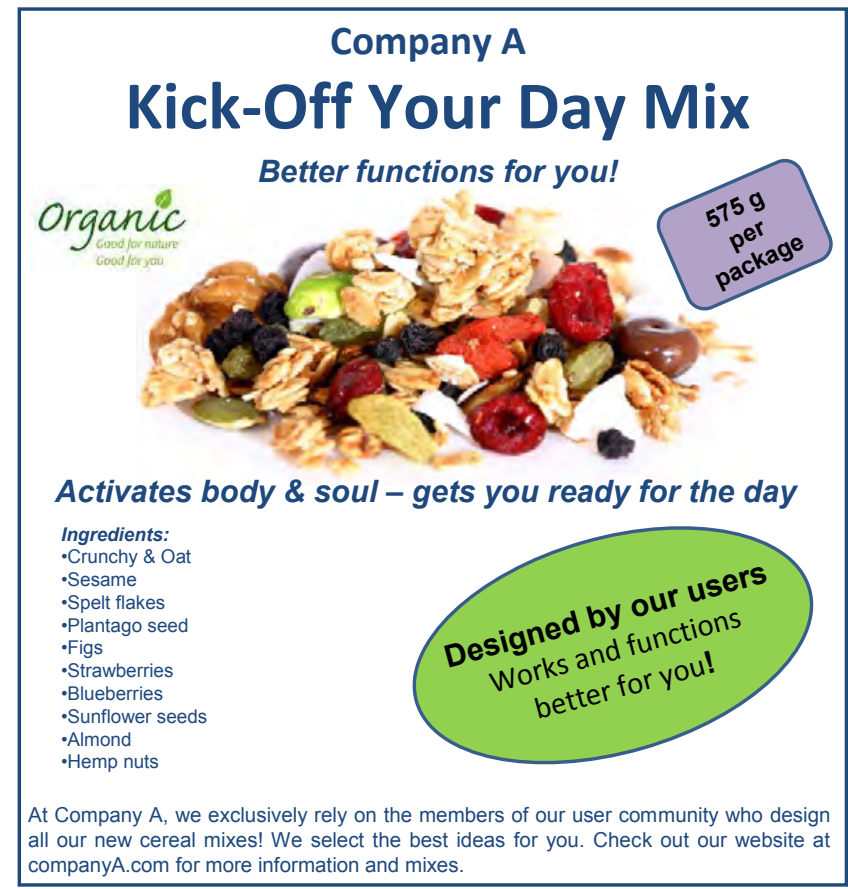

Notes: Participants saw a color picture of the packaging and were informed that the researchers "redesigned" the real package to keep the real brand blinded for research purposes and that although the real package had a fancier design, the information on it was identical. The researchers described the firm as a cereal company that focuses on cereals "that aim to increase physical and mental well-being and performance" (functionality condition) or simply as one that "focuses on tastier cereals" (aesthetic condition). Participants in the taste condition read, "A better taste for you!" (instead of "Better functions for you!"), "Gives taste \& pleasure" (instead of "Activates body \& soul"), and "Looks and tastes better for you!" (instead of "Works and functions better for you!"). Participants in the design by professional designers condition read, "Designed by our designers" (instead of "Designed by our users") and "... we exclusively rely on our professionals who ..." (instead of "... we exclusively rely on the members of our user community who ...").

\section{REFERENCES}

Aiken, Leona S. and Stephen G. West (1993), Multiple Regression: Testing and Interpreting Interactions. London: Sage Publications.

-Aiken, Michael and Jerald Hage (1966), "Organizational Analysis: A Comparative Analysis," American Sociological Review, 31 (4), 497-507.

- Barksdale, Hiram C. and William R. Darden (1972), "Consumers' Attitudes Towards the Marketing Concept," Journal of Marketing, 36 (October), 28-35.

-Bennett, Roger C. and Robert G. Cooper (1981), "The Misuse of Marketing," Business Horizons, 24 (6), 51-61.

Brown, Tom J. and Peter A. Dacin (1997), "The Company and the Product: Corporate Associations and Consumer Product Responses," Journal of Marketing, 61 (January), 68-84.

$-\ldots$, - Michael G. Pratt, and David A. Whetten (2006), "Identity, Intended Image, Construed Image, and Reputation: An Interdisciplinary Framework and Suggested Terminology," Journal of the Academy Marketing Science, 34 (2), 99-106.

Bruner, Gordon C., II, and Paul J. Hensel (2001), Marketing Scales Handbook. A Compilation of Multi-Item Measures. Chicago: American Marketing Association.

Campbell, Donald J. (1988), "Task Complexity: A Review and Analysis," Academy of Management Review, 13 (1), 40-52.

Chow, Gregory C. (1960), "Tests of Equality Between Sets of Coefficients in Two Linear Regressions," Econometrica, 28 (July), 591-605.

-Chun, Rosa and Gary Davies (2006), "The Influence of Corporate Character on Customers and Employees: Exploring Similarities and Differences," Journal of the Academy of Marketing Science, 34 (2), 138-46.

DeVellis, Robert F. (2003), Scale Development: Theory and Applications, $2 \mathrm{~d}$ ed. Thousand Oaks, CA: Sage Publications.

-Diehl, Michael and Wolfgang Stroebe (1987), "Productivity Loss in Idea-Generating Groups: Toward the Solution of a Riddle," Journal of Personality and Social Psychology, 53 (3), 497-509.

-Ding, Min (2007), "An Incentive-Aligned Mechanism for Conjoint Analysis," Journal of Marketing Research, 44 (May), 214-23.

-Fornell, Claes and David F. Larcker (1981), "Evaluating Structural Equation Models with Unobservable Variables and Measurement Error," Journal of Marketing Research, 18 (February), 39-50.

-Franke, Nikolaus, Martin Schreier, and Ulrike Kaiser (2010), "The 'I Designed It Myself' Effect in Mass Customization," Management Science, 56 (1), 125-40.

$\longrightarrow$, Eric von Hippel, and Martin Schreier (2006), "Finding Commercially Attractive User Innovations: A Test of LeadUser Theory," Journal of Product Innovation Management, 23 (4), 301-315.

-Fuchs, Christoph and Martin Schreier (2011), "Customer Empowerment in New Product Development," Journal of Product Innovation Management, 28 (January), 17-32.

Gürhan-Canli, Zeynep and Rajeev Batra (2004), "When Corporate Image Affects Product Evaluations: The Moderating Role of Perceived Risk," Journal of Marketing Research, 41 (May), 197-205.

Hobday, Mike (1998), "Product Complexity, Innovation and Industrial Organization," Research Policy, 26 (6), 689-710.

-Hoffman, Elizabeth, Dale J. Menkhaus, Dipankar Chakravarti, Ray A. Field, and Glen D. Whipple (1993), "Using Laboratory Experimental Auctions in Marketing Research: A Case Study of New Packaging for Fresh Beef," Marketing Science, 12 (3), 318-38.

-Holmes, David S. (1968), "Dimensions of Projection," Psychological Bulletin, 69 (4), 248-68.

Hong, Sung-tai and Robert Wyer Jr. (1989), "Effects of Countryof-Origin and Product-Attribute Information on Product Evaluation: An Information Processing Perspective," Journal of Consumer Research, 16 (September), 175-87. 
Huber, Joel and J.W. McCann (1982), "The Impact of Inferential Beliefs on Product Evaluations," Journal of Marketing Research, 19 (August), 324-33.

-Kardes, Frank R., Steven S. Posavac, and Maria L. Cronley (2004), "Consumer Inference: A Review of Processes, Bases, and Judgment Contexts," Journal of Consumer Psychology, 14 (3), 230-56.

Kawada, Christie L.K., Gabriele Oettingen, Peter M. Gollwitzer, and John A. Bargh (2004), "The Projection of Implicit and Explicit Goals," Journal of Personality and Social Psychology, 86 (4), 545-59.

Kruglanski, Arie W. and Donna M. Webster (1996), "Motivated Closing of the Mind: 'Seizing' and 'Freezing,'” Psychological Review, 103 (2), 263-83.

-Lettl, Christopher, Cornelius Herstatt, and Hans-Georg Gemuenden (2006), "Users' Contributions to Radical Innovation: Evidence from Four Cases in the Field of Medical Equipment Technology," R\&D Management, 36 (3), 251-72.

Luo, Xueming and C.B. Bhattacharya (2006), "Corporate Social Responsibility, Customer Satisfaction, and Market Value," Journal of Marketing, 70 (October), 1-18.

Mannix, Elisabeth and Margaret A. Neale (2005), "What Differences Make a Difference? The Promise and Reality of Diverse Teams in Organizations," Psychological Science in the Public Interest, 6 (2), 31-55.

Moreau, C. Page and Kelly B. Herd (2010), "To Each His Own? How Comparisons with Others Influence Consumers' Evaluations of Their Self-Designed Products," Journal of Consumer Research, 36 (February), 806-819.

-Morrison, Pamela D., John H. Roberts, and David F. Midgley (2004), "The Nature of Lead Users and Measurement of Leading Edge Status," Research Policy, 33 (2), 351-62.

Novak, Sharon and Steven D. Eppinger (2001), "Product Complexity and the Supply Chain," Management Science, 47 (1), 189-204.

Ogawa, Susumu and Frank T. Piller (2006), "Reducing the Risks of New Product Development," Sloan Management Review, 47 (2), 65-71.

Osborn, Alex F. (1963), Applied Imagination. New York: Charles Scribner's Sons.

-Preacher, Kristopher J. and Andrew F. Hayes (2008), “Asymptotic and Resampling Strategies for Assessing and Comparing Indirect Effects in Multiple Mediator Models," Behavior Research Methods, 40 (3), 879-91.

-Ratneshwar, S. and Shelly Chaiken (1991), "Comprehension's Role in Persuasion. The Case of Its Moderating Effect on the Persuasive Impact of Source Cues," Journal of Consumer Research, 18 (1), 52-62.

Rigby, Darell K. and Vijay Vishwanath (2006), "Localization: The Revolution in Consumer Markets," Harvard Business Review, (April), 82-92.

Rindfleisch, Aric and Christine Moorman (2001), "The Acquisition and Utilization of Information in New Product Alliances: A Strength-of-Ties Perspective," Journal of Marketing, 65 (April), 1-18.

-Robinson, Gail and Kathleen Dechant (1997), "Building a Business Case for Diversity," Academy of Management Executive, 11 (3), 21-31.

Rogers, Everett M. (1995), Diffusion of Innovations, 4th ed. New York: The Free Press.

-Ross, Lee, David Greene, and Pamela House (1977), “The 'False Consensus Effect': An Egocentric Bias in Social Perception and Attribution Processes," Journal of Experimental Social Psychology, 13 (3), 279-301.
Rotter, Julian B. (1966), "Internal-External Control and Reinforcement," Psychological Monographs, 80 (1), Whole No. 609.

-Schreier, Martin, Stefan Oberhauser, and Reinhard Prügl (2007), "Lead Users and the Adoption and Diffusion of New Products: Insights from Two Extreme Sport Communities," Marketing Letters, 18 (1/2), 15-30.

-Schulze, Anja and Martin Hoegl (2008), "Organizational Knowledge Creation and the Generation of New Product Ideas: A Behavioral Approach," Research Policy, 37 (10), 1742-50.

-Sethi, Rajesh, Daniel C. Smith, and C. Whan Park (2001), "CrossFunctional Product Development Teams, Creativity, and the Innovativeness of New Consumer Products," Journal of Marketing Research, 38 (February), 73-85.

-Spencer, Steven J., Mark P. Zanna, and Geoffrey T. Fong (2005), "Establishing a Causal Chain: Why Experiments Are Often More Effective Than Mediational Analyses in Examining Psychological Processes," Journal of Personality and Social Psychology, 89 (6), 845-51.

Strauss, Anselm and Juliet Corbin (1998), Basics of Qualitative Research: Techniques and Procedures for Developing Grounded Theory, $2 \mathrm{~d}$ ed. Thousand Oaks, CA: Sage Publications.

-Szymanski, David M., Michael W. Kroff, and Lisa C. Troy (2007), "Innovativeness and New Product Success: Insights from the Cumulative Evidence," Journal of the Academy of Marketing Science, 35 (1), 35-52.

Terwiesch, Christian and Karl T. Ulrich (2009), Innovation Tournaments: Creating and Selecting Exceptional Opportunities. Boston: Harvard Business Press.

Troy, Lisa C. and Moshe Davidow (1998), "The Relationship Between Customer-Perceived Product Innovativeness and a New Product's Potential for Success," in American Marketing Association Conference Proceedings, Vol. 9. Chicago: American Marketing Association, 127.

- _ David M. Szymanski, and Rajan P. Varadarajan (2001), "Generating New Product Ideas: An Initial Investigation of the Role of Market Information and Organizational Characteristics," Journal of the Academy of Marketing Science, 29 (1), 89-101.

Ulrich, Karl T. (2007), Design: Creation of Artifacts in Society. Philadelphia: Pontifica Press.

-Valacich, Joseph S., Bradley C. Wheeler, Brian E. Mennecke, and Renee Wachter (1995), "The Effects of Logical Group Size on Computer-Mediated Idea Generation," Organizational Behavior and Human Decision Processes, 62 (2), 318-29.

Van Gundy, Arthur B. (1988), Techniques of Structured Problem Solving. New York: John Wiley \& Sons.

-Vickrey, William (1961), "Counterspeculation, Auctions, and Competitive Sealed Tenders," Journal of Finance, 16 (1), 165-91.

Von Hippel, Eric (2005), Democratizing Innovation. Cambridge, MA: MIT Press.

- Jeroen de Jong, and Steven Flowers (2012), "Comparing Business and Household Sector Innovation in Consumer Products: Findings from a Representative Study in the UK," Management Science, (published electronically May 18), [DOI: 10.128/ mnsc.1110.1508].

Zhao, Xi, John G. Lynch, and Q. Chen (2010), "Reconsidering Baron and Kenny: Myths and Truths About Mediation Analysis," Journal of Consumer Research, 37 (August), 197-206. 